\title{
Tonometry to estimate intestinal perfusion in newborn piglets
}

\author{
Morag E Campbell, John E Van Aerde, Po-Yin Cheung, Damon C Mayes
}

\begin{abstract}
Aim-To determine the correlation between gastric intramucosal $\mathrm{pH}$ and superior mesenteric artery (SMA) flow in newborn piglets.

Methods-Fourteen newborn piglets were randomly assigned to either a control or to an epinephrine group which received $0,1,2,4,0 \mu \mathrm{g} / \mathrm{kg} / \mathrm{min}$ of epinephrine for 60 minutes, each dose. Gastric tonometry was performed, SMA flow was measured, and intramucosal $\mathrm{pH}$ and the ratio of tonometer $\mathrm{pCO}_{2}$ over arterial $\mathrm{pCO}_{2}\left(\mathrm{rCO}_{2}\right)$ were calculated.

Results-Intramucosal $\mathrm{pH}$ decreased over time in both groups, but tended to be lower in the epinephrine group. With increasing dose of epinephrine, SMA flow decreased; this in turn increased $\mathrm{rCO}_{2}(p=0.04)$ with a tendency to decrease intramucosal $\mathrm{pH}$ $(\mathbf{p}=0.06)$.

Conclusions-Gastric tonometry may be useful in human neonates to evaluate gut ischaemia.
\end{abstract}

(Arch Dis Child Fetal Neonatal Ed 1999;81:F105-F109)

Keywords: tonometry; ischemia; inotropes; bowel

Tonometry is a minimally invasive method of calculating intracellular $\mathrm{pH}$ in a hollow viscus. ${ }^{1-3}$ Intramucosal $\mathrm{pH}$ in the gastric mucosa can be estimated indirectly by measuring partial pressure of carbon dioxide $\left(\mathrm{PCO}_{2}\right)$ in the lining of the stomach with a silicone balloon catheter, and the arterial bicarbonate concentration. These two values are then substituted in the Henderson-Hasselbach equation:

$$
\mathrm{pHim}=6.1+\log \left[\mathrm{HCO}_{3}\right] /\left(\mathrm{PCO}_{2} \times 0.031\right) .
$$

For gastric tonometry, a modified gastric tube is inserted into the stomach with a silactic gas permeable balloon at the end into which $0.9 \%$ saline or phosphate buffered saline is instilled. ${ }^{4-7}$ After the buffer has equilibrated with the $\mathrm{PCO}_{2}$ in the superficial mucosa it is analysed in a blood gas analyser.

Animal studies have shown that intramucosal $\mathrm{pH}$ falls in response to haemorrhagic shock $^{8-11}$ and in mechanically induced gut ischaemia. ${ }^{12-14}$ In clinical practice, the presence of an abnormally low gastric intramucosal $\mathrm{pH}$ has been correlated with increased mortality in both critically ill adults ${ }^{15-17}$ and in children with septic shock. ${ }^{18} \mathrm{~A}$ low gastric intramucosal $\mathrm{pH}$ is a relatively frequent postoperative finding in patients who have undergone heart surgery. ${ }^{19}$

Mesenteric ischaemia is one of the factors implicated in the pathogenesis of necrotising enterocolitis. This has an incidence of 1.3 to 2.4 per 1000 live births with a reported prevalence of up to $10 \%$ in very low birthweight infants. ${ }^{20}$ Epinephrine is frequently used to treat hypotension in neonates; high doses reduce superior mesenteric artery (SMA) blood flow in newborn piglets. ${ }^{21} 22$ It is not known whether gastric tonometry correlates with mesenteric perfusion in newborn infants receiving epinephrine.

The objectives of this pilot study were to investigate whether increasing amounts of epinephrine reduce SMA flow, inducing a fall in gastric intramucosal $\mathrm{pH}$ and a rise in $\mathrm{rCO}_{2}$, and whether tonometry is a useful tool for estimating intestinal perfusion changes in the newborn piglet.

\section{Methods}

Fourteen 1-3 day old piglets (Camborough/ Canabreed) who had been fasted for a minimum of 4 hours were randomly assigned to one of two groups. After 45 minutes of stabilisation the control group was studied for 4 hours while kept anaesthetised. The study group similarly stabilised and received a stepwise increasing infusion of 1,2 , and $4 \mathrm{mcg} /$ $\mathrm{kg} / \mathrm{min}$ of epinephrine for 60 minutes for each dose, followed by 60 minutes of regular maintenance fluid without epinephrine. Both groups received $20 \mathrm{ml} / \mathrm{kg} /$ hour of $0.9 \%$ saline $/ 5 \%$ dextrose as maintenance solution.

Under general anaesthesia with halothane, a double lumen catheter was placed in the external jugular vein through a midline neck incision, while a single lumen catheter was inserted into the carotid artery. After tracheotomy and placement of an endotracheal tube, assisted ventilation was started. Animals were ventilated (Health Dyne 105 Ventilator) with room air at pressures and rates to maintain normal arterial $\mathrm{PCO}_{2}$ between 35 and $45 \mathrm{~mm}$ $\mathrm{Hg}$ and arterial $\mathrm{pH}$ between 7.30 and 7.45.

Halothane was then discontinued, boluses of ace promazine $(0.2 \mathrm{mg} / \mathrm{kg})$ and fentanyl $(10$ $\mu \mathrm{g} / \mathrm{kg}$ ) were administered followed by a continuous fentanyl infusion (10 $\mu \mathrm{g} / \mathrm{kg} /$ hour $)$. Paralysis was maintained using pancuronium bromide $(0.2 \mathrm{mg} / \mathrm{kg}$ initially followed by 0.1 $\mathrm{mg} / \mathrm{kg}$ every 60 minutes). To inhibit gastric acid production, a loading dose of ranitidine (1 $\mathrm{mg} / \mathrm{kg}$ ) was administered, followed by a continuous infusion $(0.125 \mathrm{mg} / \mathrm{kg} /$ hour $)$.

The aorta was exposed retroperitoneally by a left flank incision and the SMA was identified. A $3 \mathrm{~mm}$ extraluminal flow probe (Transonic Systems Inc., Ithaca, NY, USA) was gently placed around the SMA. After inserting the probe the incision was closed and good signals 
of flow measurement were ensured. SMA flow, mean arterial blood pressure, heart rate and pulse oximetry oxygen saturation were continuously monitored, and the analog outputs were digitised and stored on hard disc. Fifteen minute segments of the digitised data recordings at the end of each 60 minute period were analysed and averaged.

The animals were then left to stabilise for 45 minutes before baseline recordings were made. Stability was defined as variability of $10 \%$ or less for blood pressure and heart rate, oxygen saturations $>90 \%, \mathrm{pH}$ between 7.30 and 7.45 , and $\mathrm{PaCO}_{2}$ between 35 and $45 \mathrm{~mm} \mathrm{Hg}$. A tonometer catheter (TRIP 7F Sigmoid, Tonometrics Inc, Worchester, MA) was inserted into the stomach. The balloon was instilled with $2.5 \mathrm{ml}$ of a phosphate buffered saline solution and left to equilibrate for 60 minutes. Sampling was performed according to the manufacturer's recommendations and $\mathrm{PaCO}_{2}$ was measured in a standard blood gas analyser. Samples were removed before each change of epinephrine dose; each new sample had been allowed to equilibrate for 60 minutes. Epinephrine was administered using high precision intravenous pumps at $1 \mu \mathrm{g} / \mathrm{kg} / \mathrm{min}$ between 0 and 60 minutes, $2 \mu \mathrm{g} / \mathrm{kg} / \mathrm{min}$ between 60 and 120 minutes, $4 \mu \mathrm{g} / \mathrm{kg} / \mathrm{min}$ between 120 and 180 minutes and was discontinued between 180 and 240 minutes. Blood and tonometry samples were collected at baseline and at the end of every 60 minutes. Blood samples were analysed for arterial blood gases, electrolytes, glucose and lactate. For lactate analysis, blood was collected on ice, plasma was separated, and stored immediately at $-80^{\circ} \mathrm{C}$. Lactate was measured using an enzymaticspectrophotometric method (Sigma Diagnostic, St Louis, MO, USA), as described before (Sigma Diagnostics) and our laboratory achieved a linearity of $r=0.99$ at 0 to 13.3 $\mathrm{mM} / 1$ of lactate in calibration and a test-retest stability of $0.99 .^{21}$

Animals were killed at the end of the study with sodium pentobarbital $(30 \mathrm{mg} / \mathrm{kg})$. No animals died during the 4 hour recording.

Approval of the Health Sciences Animal Welfare Committee of the University of Alberta was obtained for all procedures, according to the guidelines of the Canadian Council of Animal Care.

All values are expressed as mean and standard deviation. Using ANOVA, assuming a 50\% difference in SMA flow between groups receiving $4 \mu \mathrm{g} / \mathrm{kg} / \mathrm{min}$ of epinephrine, ${ }^{22}$ and assuming a standard deviation of 15 , a minimum sample size of seven for each group would be needed to reach a power of $80 \%$ with an $\alpha$ value of 0.05 (Sigmastat 1.0 for Windows, Jandel Scientific, San Rafael, CA, USA). Differences within each group were analysed using one way repeated measures analysis of variance, between groups using two way analysis of variance, and for multiple comparisons the Student NewmanKeuls test was used. When the normality or equal variance test failed, a Kruskal-Wallis one way ANOVA on ranks was used: $p<0.05$ was considered significant.

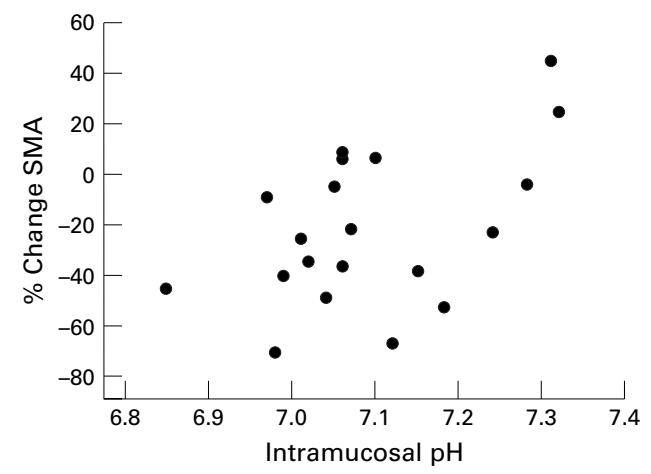

Figure 1 In the epinephrine group gastric intramucosal $p H$ decreased with decreasing $S M A$ flow $(p=0.065)$. $S M A$ flow is expressed as \% change from baseline. For the epinephrine group: 0, 60,120,180 and 240 minutes represent $0,1,2,4$, and $0 \mu \mathrm{g} / \mathrm{kg} / \mathrm{min}$ epinephrine, respectively.

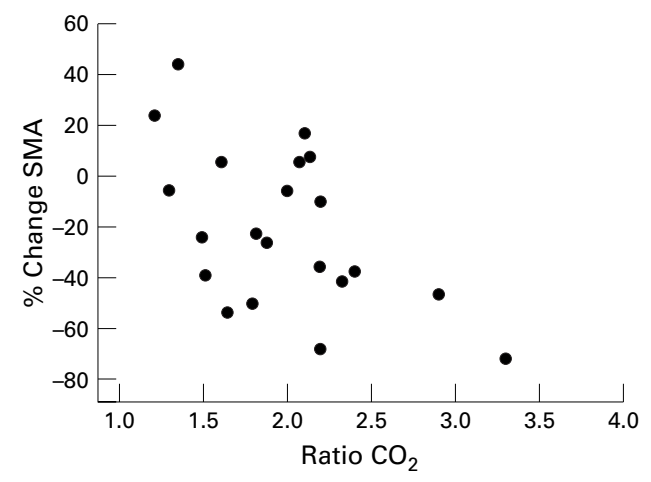

Figure 2 In the epinephrine group, $r \mathrm{CO}_{2}$ increased with decreasing SMA flow ( $p=0.04)$. SMA flow is expressed as $\%$ change from baseline. For the epinephrine group: 0, 60, 120,180 and 240 minutes represent $0,1,2,4$, and 0 $\mu \mathrm{g} / \mathrm{kg} / \mathrm{min}$ epinephrine, respectively.

Intramucosal $\mathrm{pH}$ and the ratios of $\mathrm{pCO}_{2}$ in tonometer over arterial blood $\left(\mathrm{rCO}_{2}\right)$ were calculated as follows:

$$
\begin{aligned}
& \mathrm{pHim}=6.1+\log \frac{\left[\mathrm{HCO}_{3}\right]}{\mathrm{P}_{\mathrm{t}} \mathrm{CO}_{2} \times 0.031} \\
& \mathrm{rCO}_{2}=\mathrm{P}_{\mathrm{t}} \mathrm{CO}_{2} / \mathrm{PaCO}_{2}
\end{aligned}
$$

where $\left[\mathrm{HCO}_{3}\right]$ is arterial bicarbonate concentration, $\mathrm{P}_{\mathrm{t}} \mathrm{CO}_{2}$ is tonometer partial pressure of carbon dioxide, $\mathrm{PaCO}_{2}$ is arterial partial pressure of carbon dioxide and 0.031 solubility of carbon dioxide in plasma.

Repeated measures regression analysis was used to investigate the association between the continuous variable SMA \% (percentage change from baseline for superior mesenteric artery flow during epinephrine infusion) with each of the continuous variables $\mathrm{rCO}_{2}$ and intramucosal $\mathrm{pH}$. Repeated measures regression was implemented by using the generalised linear mixed model (GLMM), as outlined in SAS System for Mixed Models 1996 (SAS Institute Inc., Cary, NC, USA). This approach allows for a regression model to be specified while adjusting for the correlated model error terms induced by repeated measurements. To ensure valid inference on model parameters it is important to choose a covariance structure that adequately reflects the 


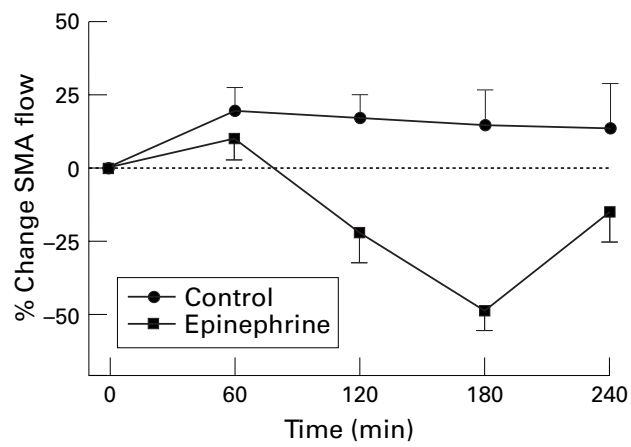

Figure $3 S M A$ flow did not change over time in the control group. SMA flow decreased significantly at 2 and 4 $\mu \mathrm{g} / \mathrm{kg} / \mathrm{min}$ of epinephrine (120 and 180 minutes) and tended to return to baseline 60 minutes after discontinuing the epinephrine infusion (240 minutes) (meantstandard error bars are shown).

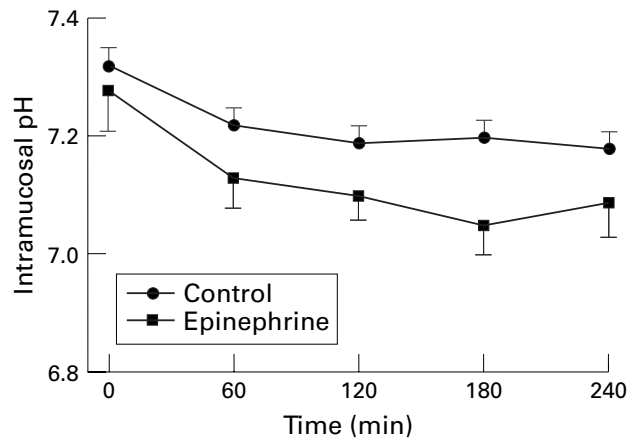

Figure 4 Gastric intramucosal $p H$ decreased between 0 and 60 minutes, after which there was no further drop in intramucosal $p H$. Although the study group has a lower intramucosal pH than control animals at all times, significance at the respective time intervals was not reached (mean \pm standard error bars are shown). For epinephrine group: 0, 60, 120, 180 and 240 minutes represent $0,1,2,4$ and $0 \mu \mathrm{g} / \mathrm{kg} / \mathrm{min}$ epinephrine, respectively.

structure of the data and the conditions under which the repeated measures were obtained. In our data the levels of the fixed within subjects factor epinephrine were not equally spaced (1, 2 , and $4 \mu \mathrm{g} / \mathrm{kg} / \mathrm{min})$. Furthermore, the amounts of epinephrine were not randomly assigned on the occasions when the observations were made. Together this information suggested that a spatial exponential covariance structure of the model errors would be appropriate. Other suitable covariance structures were also used, but the spatial exponential covariance structure resulted in the best fit regression model. Figures 1 and 2 were used to determine the functional form of the regression equations. It was felt that linear regression would adequately describe the data and hence two linear regression models were fitted to the data. The first model specified both SMA\% and an epinephrine factor (representing the doses) as the dependent variables and intramucosal $\mathrm{pH}$ as the independent variable. The second model was the same, except that $\mathrm{rCO}_{2}$ replaced intramucosal $\mathrm{pH}$ as the independent variable. Note that the between subjects effect (piglet effect) is a random effect the variability of which is accounted for by the covariance structure. For both regression models no significant interaction existed between SMA\% and the epinephrine factor (assuming a level of significance of 0.05). This implies that the effect of SMA $\%$ on either dependent variable remained constant whatever the epinephrine dose.

\section{Results}

Body weights were similar in the control $(\mathrm{n}=7$; mean (SD) 1646 (122) g) and in the epinephrine group ( $\mathrm{n}=7$; mean (SD) 1569 (253) g). Blood pressure, heart rate, blood gases, serum electrolytes and glucose remained within normal values and did not differ between the two groups at any time. Baseline SMA flows were similar in both groups. In the control group, SMA flow did not change significantly from baseline throughout the experiment. In the epinephrine group SMA flow decreased progressively with increasing doses of epinephrine in a dose dependent manner, resulting in a 21 and $48 \%$ decrease from baseline at 2 and $4 \mu \mathrm{g} / \mathrm{kg} / \mathrm{min}$, respectively (table 1) (fig 3). Compared with the control group, the epinephrine group had significantly lower SMA flows at 2 and $4 \mu \mathrm{g} / \mathrm{kg} / \mathrm{min}$ of epinephrine (table 1) (fig 3). Sixty minutes after epinephrine had been discontinued, SMA flow in the epinephrine group was no longer significantly different from that of the control group or from baseline (table 1) (fig 3). Both arterial $\mathrm{pH}$ and base excess remained stable in both control and study groups, but intramucosal pH decreased from baseline in both groups. Although there was a trend towards lower intramucosal $\mathrm{pH}$ for each dose in the epinephrine group compared with that in the control group, this was not significant (table 1) (fig 4). The ratio of tonometer over arterial $\mathrm{PCO}_{2}\left(\mathrm{rCO}_{2}\right)$ did not change during the study in the control group, but increased above baseline values in the epinephrine group. At the highest dose of epinephrine, $4 \mu \mathrm{g} / \mathrm{kg} / \mathrm{min}, \mathrm{rCO}_{2}$ and serum lactate were significantly higher than in the control group and than baseline (table 1). In the control group lactate concentrations were lower at 120 and 240 minutes than at baseline (table 1). A positive association was found between percentage change in SMA flow from baseline and intramucosal $\mathrm{pH}$

Table 1 Mean (SD) SMA flow, gastric intramucosal $p \mathrm{H}, r \mathrm{CO}_{2}$, serum lactate

\begin{tabular}{|c|c|c|c|c|c|c|c|c|}
\hline \multirow{2}{*}{$\begin{array}{l}\text { Time } \\
\text { (min) }\end{array}$} & \multicolumn{2}{|c|}{$\%$ change in SMA flow } & \multicolumn{2}{|c|}{ Gastric intramucosal pH } & \multicolumn{2}{|l|}{$r \mathrm{CO}_{2}$} & \multicolumn{2}{|c|}{ Lactate $(m M / l)$} \\
\hline & Controls & Epinephrine & Controls & Epinephrine & Controls & Epinephrine & Controls & Epinephrine \\
\hline 0 & 0 & $0^{\mathrm{a}}$ & $7.32(0.06)^{\mathrm{a}}$ & $7.28(0.17)^{\mathrm{a}}$ & $1.36(0.35)$ & $1.26(0.24)^{\mathrm{a}}$ & $3.71(1.5)^{\mathrm{a}}$ & $3.46(1.1)^{\mathrm{a}}$ \\
\hline 60 & $20.3(18.7)$ & $10.5(17.6)^{\mathrm{a}}$ & $7.22(0.07)^{\mathrm{b}}$ & $7.13(0.12)^{\mathrm{b}}$ & $1.64(0.53)$ & $1.82(0.39)^{\mathrm{b}}$ & $3.36(2.0)^{\mathrm{a}}$ & $4.39(1.2)^{\mathrm{b}}$ \\
\hline 120 & $17.9(19.1)^{\star}$ & $-21.5(25.2)^{\star \mathrm{b}}$ & $7.19(0.08)^{\mathrm{b}}$ & $7.10(0.11)^{\mathrm{b}}$ & $1.71(0.27)$ & $1.88(0.38)^{\mathrm{b}}$ & $2.83(1.4)^{\mathrm{b}}$ & $4.97(1.4)^{\mathrm{b}}$ \\
\hline 180 & $15.8(27.9)^{\star}$ & $-47.7(16.7)^{\star_{c}}$ & $7.20(0.06)^{b}$ & $7.05(0.13)^{b}$ & $1.66(0.16)^{\star}$ & $2.22(0.49)^{\star_{b}}$ & $2.13(1.2)^{\mathrm{xb}_{\mathrm{b}}}$ & $5.49(1.6)^{* b}$ \\
\hline 240 & $14.7(38.8)$ & $-14.8(24.2)^{\mathrm{a}, \mathrm{b}}$ & $7.18(0.07)^{\mathrm{b}}$ & $7.09(0.16)^{\mathrm{b}}$ & $1.71(0.32)$ & $2.15(0.72)^{\mathrm{b}}$ & $2.17(1.6)^{x_{b}}$ & $5.09(1.6)^{*_{b}}$ \\
\hline
\end{tabular}

SMA: superior mesenteric artery; $\mathrm{rCO}_{2}$ : ratio of $\mathrm{PCO}_{2}$ in tonometer over $\mathrm{PCO}_{2}$ in arterial blood; ${ }^{\star} \mathrm{p}<0.05 v$ controls

${ }^{\mathrm{a}, \mathrm{b}, \mathrm{c}} \mathrm{C}$ : numbers with different superscript are significantly different within the same column 
$(p=0.06 ;$ SMA $\%$ coefficient $0.019 ;$ SE 0.009$)$ (fig 1). Although this was not significant at the $5 \%$ level, it suggests an association. There was a significant negative association between percentage change in SMA flow from baseline and $\mathrm{rCO}_{2}(\mathrm{p}=0.04$; SMA coefficient -0.01 ; SE 0.0044) (fig 2). Both regression models fit the data adequately as indicated by Akaike's Information Criterion, Schwarz's Bayesian Criterion, and Residual Log Likelihood values.

\section{Discussion}

Tonometry can show a fall in intramucosal $\mathrm{pH}$ during haemorrhagic shock,,$^{8-11}$ in bowel ischaemia, ${ }^{12-14}$ and the presence of low intramucosal pH correlated with increased mortality. ${ }^{15-18}$ In neonates undergoing corrective cardiovascular surgery for left heart obstructive anomalies, a decrease in gastric intramucosal $\mathrm{pH}$ was shown, supporting an association between intestinal blood flow and gastric intramucosal $\mathrm{pH}^{23}$

In this pilot study we investigated the value of gastric tonometry in a newborn animal model. This model is known to develop splanchnic vasoconstriction at high epinephrine doses $^{22}$ which might allow us to determine whether changes in SMA blood flow can be used to predict gastric intramucosal $\mathrm{pH}$, and vice versa. Our preliminary data confirm that SMA flow decreases with increasing epinephrine dose, ${ }^{2122}$ returning to baseline values once epinephrine has been discontinued. However, inaccuracies in estimating intramucosal $\mathrm{pH}$ from gastric $\mathrm{pH}$ can arise through back diffusion of acid and/or production of $\mathrm{CO}_{2}$ from neutralising gastric acid by duodenal bicarbonate. By administering ranitidine, an $\mathrm{H}_{2}$-receptor blocker, we should have minimised this effect. ${ }^{24} 25$

After an initial drop within 60 minutes, gastric intramucosal $\mathrm{pH}$ was not significantly altered in either the control or epinephrine group. The fact that intramucosal $\mathrm{pH}$ dropped from baseline in both groups may have been the consequence of the surgical manipulation for line insertion and tracheostomy, or, more likely, it may have been the result of manipulating the SMA flow itself during flow probe placement. The fact that there was no significant change in SMA flow from baseline in the control group supports the fact that the haemodynamics of these animals remained stable during the 4 hour study. Moreover, arterial $\mathrm{pH}$, base excess, blood pressure, and oxygen saturations did not alter in either group for the duration of the entire study. Although there was a modest dose dependent decrease in intramucosal $\mathrm{pH}$ with epinephrine infusion, we could not show a difference between the groups for the respective epinephrine doses. It has been shown that intramucosal $\mathrm{pH}$ only falls significantly when SMA flow is reduced to less than $60 \%$ of baseline flow, ${ }^{13}$ which is about the level of SMA flow reduction the animals receiving $4 \mu \mathrm{g} / \mathrm{kg} / \mathrm{min}$ of epinephrine experienced. The three animals whose SMA flows dropped by more than $50 \%$ had the largest drop in intramucosal $\mathrm{pH}-0.3$ or more. $\mathrm{rCO}_{2}$ increased with decreasing SMA blood flow ( $\mathrm{p}$
$=0.04)$, and intramucosal $\mathrm{pH}$ tended to decrease with decreasing SMA flow $(p=0.06)$. However, the large scatter and small sample size would preclude us from accurately predicting intramucosal $\mathrm{pH}$ and/or $\mathrm{rCO}_{2}$ from SMA flow measurements. Furthermore, we used very high doses of epinephrine at 2 and 4 $\mu \mathrm{g} / \mathrm{kg} / \mathrm{min}$ to obtain circulatory and $\mathrm{pH}$ effects in the gastrointestinal system. Therefore, the usefulness of this technology remains to be established in preterm infants who probably experience much smaller changes in blood flow redistribution.

In adults intramucosal $\mathrm{pH}$ monitoring has been used to influence the timing of weaning from artificial ventilation and the introduction of enteral feeding. ${ }^{26}$ A significant fall in gastric intramucosal $\mathrm{pH}$ in association with maximal ventilatory weaning, presumably due to diversion of blood away from the intestine to the respiratory muscle system, has been reported. ${ }^{26}$ Similarly, introduction of enteral feeding has been associated with a drop in intramucosal $\mathrm{pH}$, probably as a result of the regional intestinal perfusion not being able to maintain enough blood flow to satisfy the metabolic demands of the bowel in response to feeds. ${ }^{27}$ Whereas the studies in adults investigated treatment effects on groups, individual predictability was of limited value. In preterm infants changes in mesenteric blood flow have been associated with the development of necrotising enterocolitis. ${ }^{28}$ While the role of tonometry in the critically ill neonate remains to be proved, the application may provide information supplementing the clinical management of necrotising enterocolitis or bowel ischaemia, even in the presence of normal haemodynamic and biochemical data.

Serum lactate concentrations decreased over time in the control group. Starting values are within the range of previously reported values for piglets, ${ }^{22}$ and the fact that values further decreased with time supports that our animals were not hypoxic or hypotensive. The fact that lactate increased with increasing epinephrine doses does not necessarily indicate increased lactate production due to peripheral tissue hypoxia and anaerobic respiration, but may merely reflect $\beta$-adrenoceptor stimulation at low doses of epinephrine infusion. ${ }^{26}$ Furthermore, high doses of epinephrine infusion may result in impaired hepatic use of lactate due to decreased hepatic perfusion, and/or enzymatic inhibition due to $\alpha$-stimulation. ${ }^{29} 30$

In conclusion, our pilot study shows that in newborn piglets, using epinephrine as a pharmacological means of decreasing the SMA flow, intramucosal $\mathrm{pH}$ decreases and $\mathrm{rCO}_{2}$ increases with decreasing SMA flow. Although gastric tonometry may be useful to sequentially monitor intramucosal $\mathrm{pH}, \mathrm{rCO}_{2}$, and splanchnic perfusion within the individual patient, normal reference group values need to be generated in larger groups of infants, and preferably of different gestational and postnatal ages.

This study was supported by the Medical Research Council of Canada.

Damon Mayes is supported by the Perinatal Research Centre, Edmonton, Canada. 
We thank Brenda Young, Ted Germaine, George Chan for technical assistance and Judy Minckler for secretarial support.

1 Antonsson JB, Boyle CC, Kruithoff KL, et al. Validation of tonometric measurement of gut intramural $\mathrm{pH}$ during endotoxaemia and mesenteric occlusion in pigs. $A m ~ \mathcal{F}$ Physiol 1990;259:G519-23.

2 Dawson AM, Trenchard D, Guz A. Small bowel tonometry. Assessment of small gut oxygen in dog and man. Nature 1965;206:943-4

3 Siggaard-Andersen O, Gothgen IH, Fogh-Anderson N. From in vitro to in vivo monitoring. Acta Anaesthesiol Scan 1995;39:7-13.

4 Groeneveld ABJ, Kolkman JJ. Splanchnic tonometry a review of physiology methodology and clinical applications. F Crit Care 1994;9:198-210.

5 Fiddian-Green RG. Gastric intramucosal pH, tissue oxygenation and acid base balance. Br F Anaesth 1995;74:591606

6 Guzman JA, Kruse JA. Development and validation of a technique for continuous monitoring of gastric intramucosal pH. Am f Respir Crit Care Med 1996;153:694-700.

7 Knichwitz G, Kuhmann M, Brodner G, Mertes N, Goeters C, Brüssel T. Gastric tonometry: Precision and reliability C, Brüssel T. Gastric tonometry: Precision and reliability Med 1996;24:512-16.

8 Schlichting E, Lyberg T. Monitoring of tissue oxygenation in shock: an experimental study in pigs. Crit Care Med in shock: an experin

9 Montgomery A, Hartmann M, Jonsson K, Haglund U. Intramucosal $\mathrm{pH}$ measurement with tonometer for detecting gastrointestinal ischemia in porcine hemorrhagic shock. Circ Shock 1989;29:319-27.

10 Desai VS, Weil MH, Tang W, Yang G, Bisera J. Gastric intramural pCO2 during peritonitis and shock. Chest 1993;104:1254-8.

11 Hartman M, Montgomery A, Jonsson K, Haglund U. Tissue oxygenation in hemorrhagic shock measured as transcutaneous oxygen tension, subcutaneous oxygen tension and gastrointestinal mucosal $\mathrm{pH}$ in pigs. Crit Care Med 1991;19:205-10

12 Boros M, Kaszaki J, Ordogh B, Nagy S. Intramucosal pH changes following complete segmental small intestinal ischaemia, as compared with the effects of superior ischaemia, as compared with the effects of superior

13 Grum CM, Fiddian-Green RG, Pittenger GL, Grant BJB Rothman ED, Dantzker DR. Adequacy of tissue oxygena14 Poole JW, Sammartano RJ, Boley SJ. The use of tonometry in the early diagnosis of mesenteric ischemia. Curr Surg 1989;44:21-4

15 Roumen RMH, Vreugde JPC, Goris JA. Gastric tonometry in multiple trauma patients. F Trauma 1994;36:313-16.
16 Maynard N, Bihari D, Beale R, et al. Assessment of splanchnic oxygenation by gastric tonometry in patients with nic oxygenation by gastric tonometry in patients
acute circulatory failure. $¥ A M A 1993 ; 270: 1203-10$.

17 Ivantury RR, Simon RJ, Havriliak D, Garcia C, Greenbarg J Stahl WM. Gastric mucosal pH and oxygen delivery and oxygen consumption indices in the assessment of adequacy of resuscitation after trauma: a prospective randomized study. F Trauma 1995;39:128-34.

18 Krafte-Jacobs B, Carver J, Wilkinson JD. Comparison of gastric intramucosal $\mathrm{pH}$ and standard perfusional measurements in pediatric septic shock. Chest 1995;108:220-5.

19 Uusaro A, Ruokonen E, Takala J. Gastric mucosal pH doses not reflect changes in splanchnic blood flow after cardiac surgery. Br F Anaesth 1995;74:149-54.

20 Uauy RD, Fanaroff AA, Korones SB, Phillips EA, Phillips JB, Wright LL. Necrotizing enterocolitis in very low birthweight infants: biodemographic and clinical correlates. $\mathcal{F}$ weight infants: biodem

21 Bigam DD, Jirsch DW, Barrington KJ, Cheung P-Y. Regional blood flow response to epinephrine infusion in normovolemic and hypovolemic piglets. Surg Forum 1995;46:664-6.

22 Cheung P-Y, Barrington KJ, Pearson RJ, Bigam DL, Finer NN, Van Aerde JE. Systemic, pulmonary and mesenteric perfusion and oxygenation effects of dopamine and epinephrine. Am f Respir Crit Care Med 1997;155:32-7.

23 Booker PD, Romer H, Franks R. Gut mucosal perfusion in neonates undergoing cardiopulmonary bypass. $\mathrm{Br} \quad \mathcal{F}$ Anaesth 1996;77:597-602.

24 Heard SO, Helsmoortel CM, Kent JC, Shahnarian A, Fink MP. Gastric tonometry in healthy volunteers: effects of MP. Gastric tonometry in healthy volunteers: effects of
ranitidine on calculated intramural pH. Crit Care Med 1991;19:271-4.

25 Kolkman JJ, Groeneveld AB, Meuwissen SG. Effect of ranitidine on basal and bicarbonate enhanced intragastric $\mathrm{pCO}_{2}$ : a tonometric study. Gut 1994;35:737-41.

26 Mohsenifar A, Hay A, Hay J, Lewis MI, Koerner SK. Gastric intramural $\mathrm{pH}$ as a predictor of success or failure in weaning from mechanical ventilation. Ann Intern Med 1993;119:794-8.

27 Trinder TJ, Lavery GG, Fee JP, Lowry KG. Low gastric intramucosal $\mathrm{pH}$ : incidence and significance in intensive care patients. Anaesth Intensive Care 1995;23:315-21.

28 Nowicki PT, Nankervis CA. The role of the circulation in the pathogenesis of necrotizing enterocolitis. Clin Perinatol 1994;219:219-34

29 Reverte M, Gacia-Barrada MJ, Moratinos J. Change in plasma glucose and lactate evoked by alpha and beta 2 -adrenoreceptor stimulation in conscious fasted rabbits. Fund Clin Pharmacol 1991;5:663-76.

30 Brockman RP. Effects of epinephrine on the net hepatic uptake of lactate, pyruvate and glycerol in sheep. Can $\mathcal{f}$ Physiol Pharmacol 1991;9:475-9. 